\title{
Prosthetic valve endocarditis due to Streptococcus pneumoniae
}

\author{
Ayman Natsheh", Michal Vidberg ${ }^{2}$, Reuven Friedmann ${ }^{3}$, Eli Ben-Chetrit ${ }^{4,5}$, Amos M Yinnon ${ }^{4,5^{*}}$ and Shoshana Zevin ${ }^{1}$
}

\begin{abstract}
Introduction: In the pre-antibiotic era up 10\% of cases of infective endocarditis were due to Streptococcus pneumoniae, but this association is currently exceedingly rare.

Case description: Since 1997 we have diagnosed three patients, all aged >70, with endocarditis due to S. pneumoniae. One of these three cases involved a prosthetic valve, another a prosthetic ring. All three patients completely recovered with antibiotic treatment only.

Discussion and evaluation: During the same period there were 1694 cases of pneumococcal bacteremia, of whom 395 (23\%) after age 70 . Therefore, after age 70 the prevalence of endocarditis out of all cases of pneumococcal bacteremia was $0.7 \%$. A literature review detected another 16 cases of pneumococcal PVE. The mean age of these 17 patients was $64 \pm 14 ; 10$ were female and 7 male. In most instances, symptom duration was short, $<6$ days. Valve surgery was performed in 5 cases (29\%) and 13 patients (76\%) survived.
\end{abstract}

Conclusions: Endocarditis due to S. pneumoniae is rare in the antibiotic era; even in patients with prosthetic valves its course is evidently not more virulent than with other low-virulent organisms.

Keywords: Infective endocarditis; Prosthetic valve endocarditis; Streptococcus pneumoniae; Mitral valve replacement

\section{Introduction}

In the pre-antibiotic era up to $15 \%$ of all cases of infective endocarditis (IE) were due to S. pneumoniae, but currently $<1 \%$, almost all involving native valves. Recent data have demonstrated a relative increase in the incidence of prosthetic valves as a predisposing factor for IE, from $\pm 13 \%$ in the 1970 s and 1980 s to presently 22-31\% (Fefer et al. 2002). We describe three patients with pneumococcal endocarditis diagnosed since 1997, one of whom had prosthetic valve endocarditis (PVE) which is the focus of the current paper and review 16 similar patients, previously published (Killen et al. 1970, Bruyn et al. 1990, Ugolini et al. 1986, Aguado et al. 1993. Hanson et al. 1993, Cunningham and Sinha 1995, Lefort et al. 2000, Collazos et al. 1996, Claes et al. 2000, O'Brien et al. 2011).

\footnotetext{
* Correspondence: yinnon@szmc.org.il

${ }^{4}$ Infectious Disease Unit, Shaare Zedek Medical Center, Jerusalem, Israel ${ }^{5}$ Division of Internal Medicine, Shaare Zedek Medical Center, affiliated with The Hebrew University-Hadassah Medical School, P.O. Box 3235 Jerusalem, Israel

Full list of author information is available at the end of the article
}

\section{Patient \#1}

In March 2013, an 80-year old female patient presented because of an unexpected fall. She underwent mitral valve replacement 13 years earlier with a St Jude mechanical valve. She denied fever or any other complaint. Oral temperature was $37.6^{\circ} \mathrm{C}$, mechanical heart sounds were heard, as well as a $2 / 6$ apical systolic murmur. The physical examination was otherwise unremarkable.

Laboratory tests revealed a leucocyte count of $10.800 / \mu \mathrm{L}$, hemoglobin $10.5 \mathrm{gm} / \mathrm{dL}$, and normal liver and kidney function tests. Because of unexplained fever, three blood cultures were obtained, which grew Streptococcus pneumoniae, with a minimal inhibitory concentration (MIC) of $<0.1 \mu \mathrm{g} / \mathrm{mL}$. A trans-esophageal echocardiogram (TEE) revealed a $1.1 \mathrm{~cm}$ sized vegetation attached to the prosthetic mitral valve. In spite of the large vegetation and its presence on a mechanical valve it was decided not to operate, because of the patient's fragility. The patient was treated with intravenous ceftriaxone for six weeks, and she attained complete clinical and microbiological cure. 


\section{Patient \#2}

In February 2006, an 81 year old fully alert woman was admitted because of swelling, erythema, local heat and pain in her left knee, which started several days after she fell. One year earlier she had undergone mitral valve repair because of severe mitral incompetence: after quadrangular resection annuloplasty was performed with a $30 \mathrm{~mm}$ ring. Physical examination revealed a temperature of $38^{\circ} \mathrm{C}$, a $1 / 6$ pan-systolic murmur at the apex, while the left knee was swollen, red and hot. The physical examination was otherwise unremarkable. The peripheral blood count was $9.400 / \mu \mathrm{L}$, hemoglobin was $9.9 \mathrm{gm} / \mathrm{dL}$ and biochemistry was normal. Streptococcus pneumoniae was isolated from two blood cultures and from joint fluid; MIC was $0.02 \mu \mathrm{g} / \mathrm{mL}$. The TEE demonstrated two vegetations $<1 \mathrm{~cm}$ in size attached to the posterior repaired mitral valve and ring. The patient received a six weeks course of ceftriaxone and completely recovered.

\section{Patient \#3}

A 74 year male patient was admitted in 1996 because of an acute febrile illness. There were no localizing symptoms and physical examination was negative except a 2/6 systolic murmur. Streptococcus pneumoniae $(\mathrm{MIC}=0.01 \mu \mathrm{g} / \mathrm{mL})$, was isolated from two blood cultures. A TEE indicated moderate mitral regurgitation, exactly as found in a routine echocardiogram obtained two years earlier. The patient received two weeks of intravenous penicillin and completely recovered. During the subsequent six months he developed exertional dyspnea without fever. Echocardiography showed significantly worsened mitral regurgitation, but no vegetations were detected. He underwent an uneventful valve replacement with a biological prosthesis. Routine histologic examination revealed an ulcerated mitral valve, with fibrinous vegetation and inflammatory infiltrate. The patient was treated with ceftriaxone for four weeks and attained complete cure. In retrospect, it seems this patient suffered from pneumococcal endocarditis, partially treated with two weeks of intravenous penicillin and subsequently developed latent endocarditis and worsening mitral insufficiency (Shapiro et al. 2004).

\section{Discussion}

Pneumococcal endocarditis in the antibiotic era is rare and generally manifests acutely, similar to staphylococcal endocarditis, although rare instances of a more insidious course have been described. In several series of pneumococcal bacteremia in the antibiotic era the prevalence rate of endocarditis was reported, which ranges from $0.3 \%$ 3.4\% (Bruyn et al. 1990, Cunningham and Sinha 1995).

In our hospital 1694 patients have been diagnosed with pneumococcal bacteremia since 1997 (Table 1). During this period only three patients, all aged $>70$,
Table 1 Patient specific episodes of S. pneumoniae bacteremia, by age (1997-2013)

\begin{tabular}{|c|c|c|c|c|c|c|}
\hline \multirow[t]{3}{*}{ Year } & \multicolumn{4}{|c|}{ Age groups (years) } & \multicolumn{2}{|c|}{ S. pneumoniae/All positive } \\
\hline & \multirow[t]{2}{*}{$1-20$} & \multirow[t]{2}{*}{$21-70$} & \multirow[t]{2}{*}{$71-110$} & \multirow[t]{2}{*}{ UA } & Total (n, \%) & All positive ${ }^{2}$ \\
\hline & & & & & \multicolumn{2}{|c|}{ S. pneumoniae ${ }^{1}$} \\
\hline 1997 & 36 & 13 & $13^{*}$ & & $62(1.4)$ & 439 \\
\hline 1998 & 42 & 39 & 22 & & $62(0.7)$ & 848 \\
\hline 1999 & 43 & 33 & 18 & & $94(1.3)$ & 708 \\
\hline 2000 & 40 & 27 & 20 & & $87(1.7)$ & 523 \\
\hline 2001 & 41 & 15 & 22 & & $78(0.9)$ & 891 \\
\hline 2002 & 52 & 21 & 11 & 2 & $84(1)$ & 876 \\
\hline 2003 & 73 & 12 & 13 & & $98(1.1)$ & 888 \\
\hline 2004 & 46 & 14 & 21 & & $81(1)$ & 789 \\
\hline 2005 & 48 & 34 & 37 & & $119(1.3)$ & 891 \\
\hline 2006 & 62 & 46 & $24^{*}$ & & $132(1.4)$ & 951 \\
\hline 2007 & 66 & 33 & 19 & 1 & $118(1.1)$ & 1029 \\
\hline 2008 & 63 & 39 & 47 & 2 & $149(1.5)$ & 997 \\
\hline 2009 & 89 & 28 & 31 & & $148(1.4)$ & 1087 \\
\hline 2010 & 54 & 25 & 24 & & $103(0.9)$ & 1176 \\
\hline 2011 & 60 & 20 & 30 & & $110(0.9)$ & 1191 \\
\hline 2012 & 45 & 19 & 31 & & $95(0.8)$ & 1205 \\
\hline 2013 & 11 & 10 & $12^{*}$ & & $33(0.3)$ & 839 \\
\hline Total & 871 & 428 & 395 & 5 & $1694(1.0)$ & 16515 \\
\hline
\end{tabular}

UA, unavailable; each asterix* indicates one patient diagnosed that particular year with $S$. pneumoniae endocarditis.

The difference in incidence of $S$. pneumoniae endocarditis between age 1-20 $(0 / 871)$, adults aged $21-70(0 / 428)$ and elderly (3/395 or $0.8 \%)$ was statistically insignificant.

All patient-specific blood isolates of S. pneumoniae ${ }^{1}$ ( $n$, and as $\%$ of all patientspecific true-positive blood isolates ${ }^{2}$ (i.e. excluding contaminants).

were diagnosed with endocarditis, constituting $0.18 \%$ of all cases of pneumococcal bacteremia. Of these 1694 cases, 395 (23\%) occurred after age 70 . Therefore, after the latter age the prevalence of endocarditis out of all cases of pneumococcal bacteremia was $0.7 \%$.

One of our three pneumococcal endocarditis cases involved a prosthetic valve, another a repaired mitral valve and ring, possibly suggesting a higher propensity of S. pneumoniae to infect prosthetic rather than natural valves. This trend has not previously been reported: the Bruyn et al. reported five patients with pneumococcal endocarditis of whom one had PVE Bruyn et al. (1990)), and Lefort et al. (2000) reported 30 cases with pneumococcal endocarditis, collected in a nation-wide survey of whom 4 (13\%) had PVE.

A literature review detected another 16 cases of PVE with this organism (Table 2). The mean age of these 17 patients was $64 \pm 14$; 10 were female and 7 male. In most instances, symptom duration was short, $<6$ days. Valve surgery was performed in 5 cases $(29 \%)$ and 13 patients (78\%) survived. 
Table 2 Reported patients with prosthetic valve endocarditis associated with Streptococcus pneumoniae

\begin{tabular}{|c|c|c|c|c|c|c|c|c|c|}
\hline No, [ref] & Year & Sex, age & Valve & PMH & Days of symptoms & Source of infection & Diagnostic method & Valve surgery & Outcome \\
\hline 1 [Killen et al. 1970] & 1970 & $M, 24$ & Aortic & NA & 5 & NA & NA & Yes & Died \\
\hline 2 [Killen 1970] & 1970 & $F, 51$ & Tricuspid & NA & 3 & NA & NA & No & Died \\
\hline 3 [Buyn 1990] & 1982 & $F, 71$ & Mitral & $\mathrm{CHF}$ & NA & Lung & No vegetations & No & Cure \\
\hline 4 [Ugolini et al. 1986] & 1986 & $M, 50$ & Aortic & DM & 5 & Sinusitis & Clinical suspicion & No & Cure \\
\hline 5 [Bruyn et al. 1990] & 1990 & $F, 71$ & Mitral & None & 1 & Lung & Clinical suspicion & No & Cure \\
\hline 6 [Aguado et al. 1993] & 1993 & $M, 53$ & Aortic & NA & NA & $\mathrm{Na}$ & NA & Yes & Cure \\
\hline 7 [Aguado et al. 1993, 1993] & 1993 & $F, 74$ & Mitral & None & 1 & Dental procedure & TEE & No & Cure \\
\hline 8 [Cunningham and Sinha 1995] & 1994 & $M, 63$ & Aortic + mitral & Previous IE & 14 & - & Clinical suspicion & No & Cure \\
\hline 9 [Lefort 2000] & 1994 & $F, 80$ & Aortic + mitral & Alcoholism DM & 30 & Unknown & TEE & Yes & Cure \\
\hline 10 [Lefort et al. 2000] & 1994 & $F, 79$ & Aortic + mitral & None & NA & Lung & No vegetation & No & Cure \\
\hline 11 [Lefort et al. 2000] & 1995 & M, 73 & Aortic & None & 21 & Lung & TEE & Yes & Died \\
\hline 12 [Cunningham and Sinha 1995] & 1995 & $M, 63$ & Mitral & None & 7 & Unknown & Clinical suspicion & No & Cure \\
\hline 13 [Lefort et al. 2000] & 1996 & $M, 58$ & Mitral & Alcoholism & 46 & Lung & TEE & No & Died \\
\hline 14 [Collazos et al. 1996] & 1996 & $F, 61$ & Mitral & None & 6 & Unknown & TEE & No & Cure \\
\hline 15 [Claes et al. 2000] & 1999 & $F, 61$ & Aortic + mitral & Atrial fib & NA & Lung & TEE & Yes & Cure \\
\hline 16 [O'Brien et al. 2011] & 2011 & $F, 63$ & Aortic & Previous IE & - & - & Roth spots + BCs & No & Cure \\
\hline 17 Present patient \#1 & 2013 & $\mathrm{~F}, 80$ & Mitral & None & NA & Unknown & TEE & No & Cure \\
\hline
\end{tabular}

Atrial Fib, atrial fibrillation; BC, blood cultures; CHF, congestive heart failure; DM, diabetes mellitus; NA: data not available; PMH, past medical history; Present 1/2, Present case 1/2; TEE, transesophageal echocardiogram; Valve, infected mechanical or biological prosthetic valve. Patient no. 2 had endocarditis from both Staphylococcus aureus and Streptococcus pneumoniae. 
In conclusion, in the antibiotic era endocarditis due to Streptococcus pneumoniae is rare. Importantly, even in patients with pneumococcal PVE its course may be insidious and not more aggressive than with other lowvirulent organisms.

\section{Competing interest}

The authors declare that they have no conflict of interest.

\section{Authors' contributions}

AN wrote the first two cases and collected previously reported patients. MV and RF verified all data and Table 2 and wrote the third case. EBC collected the laboratory data. AMY and SZ are responsible for the academic content and wrote the discussion. All authors read and approved the final manuscript.

\section{Author details}

'Department of Medicine B, Shaare Zedek Medical Center, Jerusalem, Israel. ${ }^{2}$ Department of Medicine A, Shaare Zedek Medical Center, Jerusalem, Israel. ${ }^{3}$ Department of Geriatrics, Shaare Zedek Medical Center, Jerusalem, Israel. ${ }^{4}$ Infectious Disease Unit, Shaare Zedek Medical Center, Jerusalem, Israel.

${ }^{5}$ Division of Internal Medicine, Shaare Zedek Medical Center, affiliated with The Hebrew University-Hadassah Medical School, P.O. Box 3235 Jerusalem, Israel.

Received: 20 May 2014 Accepted: 15 July 2014

Published: 22 July 2014

\section{References}

Aguado JM, Casillas A, Lizasoaín M, Lumbreras C, Peña C, Martín-Durán R, Fernández-Viladrich P, Fernández-Guerrero ML, Noriega AR (1993) Endocarditis por neumococos sensibles y resistentes a penicilina: prespectivas actuales de la enfermedad. Med Clin (Barc) 100:325-328

Bruyn GA, Thompson J, Van der Meer JW (1990) Pneumococcal endocarditis in adult patients. A report of five cases and review of the literature. Q J Med 74:33-40

Claes K, De Man F, Van de Werf F, Peetermans WE (2000) Double prosthetic valve endocarditis caused by Streptococcus pneumoniae. Infection 28:51-52

Collazos J, García-Cuevas M, Martinez E, Mayo J, Lekuona I (1996) Prosthetic valve endocarditis due to Streptococcus pneumoniae. Arch Intern Med $156: 2141-2148$

Cunningham R, Sinha L (1995) Recurrent Streptococcus pneumoniae endocarditis. Eur J Clin Microbial Infect Dis 14:526-528

Fefer P, Raveh D, Rudensky B, Schlesinger Y, Yinnon AM (2002) Changing epidemiology of infective endocarditis: a retrospective survey of 108 cases, 1990-1999. Eur J Clin Microbiol Infect Dis 21:432-437

Hanson B, Bar JP, Coppens L, Korman D, Lustman F (1993) Pneumococcal endocarditis on an artifical mitral valve. Am J Med 95:451-452

Killen DA, Collins HA, Koenig MG, Goodman JS (1970) Prosthetic cardiac valves and bacterial endocarditis. Ann Thorac Surg 9:238-247

Lefort A, Mainardi JL, Selton Suty C, Casassus P, Guillevin L, Lortholary O, The Pneumococcal Endocarditis Study Group (2000) Streptococcus pneumoniae endocarditis in adults. A multicentric study in France in the era of penicillin resistance (1991-1998). Med (Baltimore) 79:327-337

O'Brien S, Dayer M, Benzimra J, Hardman S, Townsend M (2011) Streptococcus pneumoniae endocarditis on replacement aortic valve with panopthalmitis and pseudoabscess. BMJ Case Rep doi:10.1136/bcr.06.2011.4304

Shapiro N, Merin O, Rosenmann E, Dzigivker I, Bitran D, Yinnon AM, Silberman S (2004) Prevalence and epidemiology of unsuspected endocarditis detected after elective valve replacement. Ann Thorac Surg 78:1623-1629

Ugolini V, Pacifico A, Smitherman TC, Mackoviak PA (1986) Pneumococcal endocarditis update: analysis of 10 cases diagnosed between 1974 and 1984. Am Heart J 112:813-819

doi:10.1186/2193-1801-3-375

Cite this article as: Natsheh et al:: Prosthetic valve endocarditis due to Streptococcus pneumoniae. SpringerPlus 2014 3:375.

\section{Submit your manuscript to a SpringerOpen ${ }^{\circ}$ journal and benefit from:}

- Convenient online submission

- Rigorous peer review

- Immediate publication on acceptance

- Open access: articles freely available online

- High visibility within the field

- Retaining the copyright to your article

Submit your next manuscript at $\boldsymbol{\wedge}$ springeropen.com 